\title{
Engagement of ubiquitination and de-ubiquitination at rostral ventrolateral medulla in experimental brain death
}

\author{
Carol HY Wu ${ }^{1,2}$, Julie YH Chan ${ }^{1}$, Jimmy Li-Jer Chou', Samuel HH Chan ${ }^{1}$ and Alice YW Chang ${ }^{1 *}$
}

\begin{abstract}
Background: Whereas brain death is a vitally important clinical phenomenon, our contemporary understanding on its underlying cellular mechanisms remains elusive. This study evaluated whether the ubiquitin-proteasome system (UPS) in the rostral ventrolateral medulla (RVLM), a neural substrate that our laboratory identified previously to be intimately related to brain death, is engaged in this fatal process.

Methods: We performed proteomics, Western Blot, real-time PCR, ELISA and pharmacological experiments in conjunction with a clinically relevant experimental endotoxemia model of brain death based on intravenous administration of Escherichia coli lipopolysaccharide in adult male Sprague-Dawley rats.
\end{abstract}

Results: Proteomics, Western blot and enzyme activity analyses demonstrated that polyubiquitination was preserved and de-ubiquitination by ubiquitin C-terminal hydrolase isozyme-L1 (UCH-L1) was sustained, alongside increased monoubiquitin availability or proteasome activity in RVLM over the course of experimental endotoxemia. However, real-time PCR revealed no significant alteration in proteasome subunit alpha type-1, ubiquitin or UCH-L1 at mRNA level. Functionally, whereas microinjection into the bilateral RVLM of proteasome inhibitors (lactacystin or proteasome inhibitor II) potentiated survival, an inhibitor of ubiquitin-recycling (ubiquitin aldehyde) or an UCH-L1 inhibitor exacerbated mortality.

Conclusions: We proposed previously that the progression towards brain death entails a tug-of-war between pro-death and pro-life programs in RVLM. It is conceivable that ubiquitination or de-ubiquitination in RVLM participate in brain death by regulating the degradation of the proteins involved in those programs.

\section{Background}

Brain death is a clinical condition in which brain functions are demonstrated to be irreversibly absent [1]. Despite its paramount importance as a medical phenomenon, there is a dearth of information on its mechanistic underpinnings. Based on a computer algorithm that our laboratory developed for online and real-time spectral analysis of systemic arterial blood pressure (SAP) signals [2], we identified previously in a series of clinical studies that a common denominator exists in comatose patients who succumbed to systemic inflammatory response syndrome [3], organophosphate poisoning [4] or brain injury [5]. Death is invariably preceded by a dramatic reduction or loss in the

\footnotetext{
* Correspondence: cgmf.kmc@gmail.com

${ }^{1}$ Center for Translational Research in Biomedical Sciences, Kaohsiung Chang Gung Memorial Hospital, Kaohsiung 83301, Taiwan, Republic of China Full list of author information is available at the end of the article
}

low-frequency (LF) component $(0.004$ to $0.15 \mathrm{~Hz})$ of the SAP spectrum. More importantly, whereas the LF spectral component is present in healthy subjects and patients in a persistent vegetative state, it is absent in patients diagnosed as brain dead [5]. Subsequent animal studies traced the origin of this clinical predictor of brain death to the rostral ventrolateral medulla (RVLM) in the brain stem [6]. We thus have in our hands a suitable neural substrate for the delineation of the cellular mechanisms that underpin brain death [7].

It is now clear that degradation of cellular proteins engages a highly complex, temporally controlled, and tightly regulated process that plays a major role in a variety of cellular processes during life and death as well as health and disease [8]. Most proteins in the cytosol and nucleus of eukaryotic cells are degraded via the ubiquitin-proteasome system (UPS), in a process that is energy-dependent. The 
highly conserved 76 amino acid protein ubiquitin is best known for its role in targeting proteins for proteasomal degradation. The active sites of the proteasome are protected from the cellular environment in the interior of the barrelshaped $20 \mathrm{~S}$ structure. Polyubiquitinated proteins are recognized by the regulatory $19 \mathrm{~S}$ complexes of the proteasome, which unfold the protein substrates and assist in their translocation through a narrow gate into the $20 \mathrm{~S}$ core where degradation takes place $[8,9]$. The ubiquitin chain is released from the target protein remnant after the degradative process and is disassembled by de-ubiquitinating enzymes that include the ubiquitin $\mathrm{C}$-terminal hydrolases (UCHs) [10]. The UCHs are responsible for the removal of small peptide fragments from the ubiquitin chain to generate free monomeric ubiquitin $[10,11]$. Of the three known mammalian members of the $\mathrm{UCH}$ family, $\mathrm{UCH}$ isozyme-L1 (UCH-L1) is among the most abundantly present proteins in brain [12].

We reported in a recent proteomic study [13] that key members of the UPS are present in RVLM at both mRNA and protein levels. The present study assessed the hypothesis that both ubiquitination and de-ubiquitination at RVLM are engaged in brain death.

\section{Materials and methods}

All experimental procedures carried out in this study have been approved by the Institutional Animal Care and Use Committee of the Kaohsiung Chang Gung Memorial Hospital (\#96008), and were in compliance with the guidelines for animal care and use set forth by this committee.

\section{Animals}

Adult, male Sprague-Dawley rats (206-248 g; $\mathrm{n}=322$ ) were purchased from the Experimental Animal Center of the National Applied Research Laboratories, Taiwan. They were housed in our Association for Assessment and Accreditation of Laboratory Animal Care Internationalaccredited Center for Laboratory Animals under temperature control $\left(24 \pm 0.5^{\circ} \mathrm{C}\right)$ and 12-h light-dark cycle (lights on during 08:00-20:00). Standard laboratory rat chow and tap water were available ad libitum. Animals were allowed to acclimatize for at least 7 days prior to experimental manipulations.

\section{General preparation}

Under an initial pentobarbital sodium anesthesia (50 mg kg-1, IP), the trachea was intubated and the right femoral artery and both femoral veins were cannulated. Animals received thereafter intravenous infusion of propofol (Zeneca, Macclesfield, UK) at $20 \mathrm{mg} \mathrm{kg}^{-1} \mathrm{~h}^{-1}$. This scheme provides satisfactory anesthetic maintenance while preserving the capacity of central cardiovascular regulation [14]. The head of animals was fixed to a stereotaxic headholder (Kopf, Tujunga, CA, USA), and body temperature was maintained at $37^{\circ} \mathrm{C}$ with a heating pad. Animals were allowed to breathe spontaneously with room air during the recording session.

\section{Experimental endotoxemia model of brain death}

An experimental endotoxemia model of brain death [7] was used, employing intravenous administration of Escherichia coli lipopolysaccharide (LPS; serotype 0111:B4, Sigma-Aldrich, St. Louis, MO, USA) (15 mg $\left.\mathrm{kg}^{-1}\right)$ as the insult, with saline serving as the vehicle control in some experiments. Temporal changes in SAP recorded from the femoral artery were routinely followed for $240 \mathrm{~min}$. The SAP signals were also subject simultaneously to on-line and real-time power spectral analysis [2]. We were particularly interested in the LF $(0.25-0.8 \mathrm{~Hz})$ component in the SAP spectrum because its power density represents the most crucial link between our animal model and clinical observations from patients who died of systemic inflammatory response syndrome [3]. As we reported previously [15-17], the LF spectral component underwent triphasic changes that composed of a reduction (Phase I), augmentation (Phase II) and disappearance (Phase III) of its power density. Of note is that the last phase resembles that observed in our brain dead patients [5].

\section{Index for mortality}

We assessed mortality by constructing a survival curve over $240 \mathrm{~min}$ after intravenous administration of LPS. Animals that succumbed to experimental endotoxemia exhibited a dramatic reduction of loss in the power density of the LF component of SAP signals before death [1517].

\section{Collection of tissue samples from RVLM}

We routinely collected tissue samples from RVLM [15-17] at the peak of each phase of experimental brain death. Medullary tissues collected from anesthetized animals but without treatment served as shamcontrols. Tissues from both sides of the ventrolateral medulla, at the level of RVLM (0.5 to $1.5 \mathrm{~mm}$ rostral to the obex), were collected by micropunches made with a $1 \mathrm{~mm}$ (id) stainless steel bore to cover the anatomical boundaries of RVLM. The concentration of total proteins extracted was determined by the BCA Protein Assay (Pierce, Rockford, IL, USA).

\section{Sample preparation for proteomic and western blot analysis}

As in previous studies $[13,18,19]$, samples from RVLM were mixed with a tissue protein extraction reagent that contains protease inhibitor and T-PER (Roche, Basel, Switzerland). After being homogenized on ice, the mixture was centrifuged at 10,000 rpm. The supernatant was concentrated by 
precipitation overnight at $-20^{\circ} \mathrm{C}$ using $10 \%$ trichloroacetic acid (TCA) and $0.1 \%$ dithiothreitol (DTT), followed by centrifugation at $13,000 \mathrm{rpm}$ at $4^{\circ} \mathrm{C}$. The pellet was airdried after being washed twice with ice-cold acetone, and was reconstituted with a rehydration solution (2\% 3-[(3cholamidopropyl)-dimethylammonio]-1-propanesulfonate, $0.5 \%$ immobilized $\mathrm{pH}$ gradient (IPG) buffer, $8 \mathrm{M}$ urea, $15 \mathrm{mM}$ DTT and trace bromophenol blue).

\section{2-Dimensional electrophoresis (2-DE)}

The methods for 2-DE in a recent study [13] were used. In brief, isoelectric focusing (IEF) in the first dimension was carried out with immobiline DryStrip gels $(13 \mathrm{~cm}$ in length, linear $\mathrm{pH}$ gradient 3-10; GE Healthcare, Piscataway, NJ, USA). The gels were rehydrated for $16 \mathrm{~h}$ with $300 \mu \mathrm{L}$ rehydration solution covered by mineral oil, with the strips placed gel-side-down in an IPGphor strip holder (Amersham Pharmacia Biotech, Piscataway, NJ, USA). An IPGphor Isoelectric Focusing System (Amersham Pharmacia Biotech) was used for IEF, which was carried out at $20^{\circ} \mathrm{C}$. A three-phase program was used for both analytical and preparative gels. The first phase was set at $500 \mathrm{~V}$ for $1 \mathrm{~h}$, the second at $1,000 \mathrm{~V}$ for $1 \mathrm{~h}$, and the third at a linear gradient spanning from $8,000 \mathrm{~V}$ to $16,000 \mathrm{~V}$ for $2 \mathrm{~h}$. After the IEF run, the IPG gel strips were kept at $-80^{\circ} \mathrm{C}$ or prepared directly for second-dimension electrophoresis.

The IPG gel strips were incubated at room temperature prior to second-dimension electrophoresis in a sodium dodecyl sulfate (SDS) equilibration solution $(50 \mathrm{mM}$ Tris- $\mathrm{HCl}, \mathrm{pH}$ 8.8, $6 \mathrm{M}$ urea, 2\% SDS, 30\% glycerol, and trace bromophenol blue) that contains 1\% DTT; to be followed by incubation in SDS equilibration solution that contains $2.5 \%$ iodoacetamide. Second dimension run on the gels was carried out at $4^{\circ} \mathrm{C}$ on running SDS-PAGE gels $(16 \times 15 \mathrm{~cm})$ without stacking using a Hoefer SE 600 (Amersham Pharmacia Biotech), and the IPG gel strips were embedded on top of the gels with $1 \%$ agarose. Electrophoresis was performed at $30 \mathrm{~mA} /$ gel for $5 \mathrm{~h}$ until bromophenol blue reached the bottom of the gel, after which the 2-D gels were stained with either Coomassie blue or silver nitrate.

The silver-stained 2-D gels were scanned in an ImageScanner II (Amersham Pharmacia Biotech), and the images were processed using Adobe Photoshop and PowerPoint software. Protein spots were checked manually to eliminate poorly detectable spots or artifacts due to gel distortion during silver staining, after which they were quantified and numbered using ImageMaster 2D Platinum (GE Healthcare). For this purpose, the intensity of each detected spot was first determined by ImageMaster, followed by computation of the area at $75 \%$ of the spot intensity. The volume of each spot in the 2-D gel was calculated based on these two parameters, and the relative volume of each spot was expressed as a percentage of the total volume of all quantified spots.

\section{In-gel digestion and MALDI-TOF mass spectrometry}

As in a recent proteomics study [13], protein spots excised from the Coomassie blue-stained gels were destained with $0.2 \mathrm{ml}$ acetonitrile and dried in a centrifugal evaporator. After rehydration in $10 \mathrm{mM}$ DTT, alkylated with $100 \mathrm{mM}$ iodoacetamide, the dried gels were digested on ice with digestion buffer made of $0.02 \mathrm{mg} / \mathrm{ml}$ trypsin gold (mass spectrometry grade; Promega, Madison, WI, USA) and $50 \mathrm{mM}$ $\mathrm{NH}_{4} \mathrm{HCO}_{3}$. After removing excess solution, proteins were further digested for $15 \mathrm{~h}$ at $37^{\circ} \mathrm{C}$. Peptides extracted with $50 \%$ acetonitrile in $5 \%$ formic acid were desalted and concentrated using in-tip reversed-phase resin (Zip Tip C18; Millipore, Billerica, MA, USA). Peptide mixtures were applied to the sample target and air-dried after being eluted from the Zip Tip with $0.1 \%$ trifluoroacetic acid (TFA) in $50 \%$ acetonitrile. After mixing with the matrix ( $\alpha$-cyano-4hydroxycinnamic acid dissolved in 50\% acetonitrile, $0.1 \%$ TFA), the sample was analyzed in a MALDI-TOF mass spectrometer system (Voyager DE-PRO, Applied Biosystems, Foster City, CA, USA) [13,18,19].

We measured the peptide masses as mono-isotopic masses. Peptide mass fingerprinting was searched against the NCBI database using MASCOT 2.1 (Matrix Science, Boston, MA, USA). Settings in the algorithm included Rattus as taxonomy, trypsin as enzyme, maximum of one missed cleavage site and assuming carbamidomethyl as a fixed modification of cysteine and oxidized methionine as a variable modification. Mass tolerance was set to $100 \mathrm{ppm}$.

\section{Western blot analysis}

Western blot analysis [13,15-19] was carried out using a rabbit polyclonal antiserum against UCH-L1 (Santa Cruz, Santa Cruz, CA, USA); or a mouse monoclonal antiserum against ubiquitin (Santa Cruz) or $\beta$-actin (Chemicon, Temecula, CA, USA). This was followed by incubation with horseradish peroxidase-conjugated donkey anti-rabbit IgG (Amersham Biosciences, Little Chalfont, Bucks, UK) for UCH-L1; or sheep anti-mouse IgG (Amersham Biosciences) for ubiquitin or $\beta$-actin. Specific antibody-antigen complex was detected by an enhanced chemiluminescence Western blot detection system (Santa Cruz). The amount of protein was quantified by the ImageMaster Video Documentation System software (Amersham Biosciences), and was expressed as the ratio relative to $\beta$-actin protein.

\section{Isolation of RNA and real-time polymerase chain reaction (PCR)}

Total RNA was isolated with TRIzol reagent (Invitrogen, Carlsgad, CA, USA). All RNA isolated was quantified by spectrophotometry and the optical 
density 260/280 $\mathrm{nm}$ ratio was determined. As in our previous studies $[13,16]$, reverse transcriptase reaction was performed using a SuperScript Preamplification System (Invitrogen) for the first-strand cDNA synthesis. Real-time PCR analysis was performed by amplification of cDNA using a LightCycler ${ }^{\bullet}$ (Roche). PCR reaction for each sample was carried out in duplicate for all the cDNA and for the GAPDH control. Primers were designed using the sequence information of the NCBI database by Roche LightCycler ${ }^{\bullet}$ probe design software 2.0, and oligonucleotides were synthesized by Genemed Biotechnologies (Taipei, Taiwan).

The primer pairs used for amplification of target genes were:

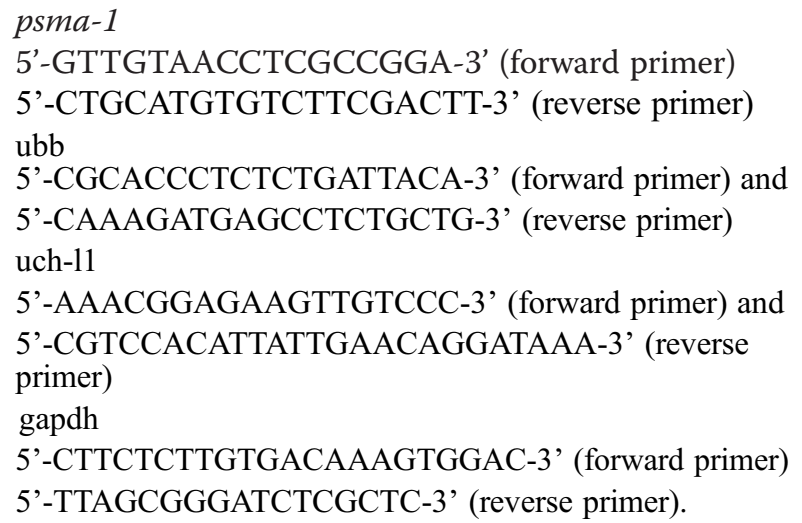

Fluorescence signals from the amplified products were quantitatively assessed using the LightCycler ${ }^{\oplus}$ software program (version 3.5; Roche). Second derivative maximum mode was chosen with baseline adjustment set in the arithmetic mode. The relative changes in mRNA expression were determined by the fold-change analysis in which

$$
\begin{aligned}
\text { Fold change } & =2^{-[\Delta \Delta C t]}, \text { where } \Delta \Delta C t \\
& =\left(C t_{\text {gene }}-C t_{G A P D H}\right)_{\text {LPS treatment }} \\
& \left.-\left(C t_{\text {gene }}-C t_{G A P D H}\right)_{\text {sham control }}\right) .
\end{aligned}
$$

Note that $\mathrm{Ct}$ value is the cycle number at which fluorescence signal crosses the threshold.

\section{Proteasome activity}

We measured proteasome activity with a commercial kit (Proteasome-Glo 3-Substrate System; Promega, Madison, WI) according to the recommended protocol. Proteins extracted from the ventrolateral medulla were incubated with proteasome-Glo reagent at room temperature for $2 \mathrm{~h}$. For the purpose of the present study, we used the luminogenic substrates provided for the detection of chymotrypsin-like activity, SucLLVY-aminoluciferin; trypsin-like activity, Z-LRR- aminoluciferin and caspase-like activity, Z-nLPnLDaminoluciferin. Proteasome activity was measured with a luminometer (Berthold Technologies, Bad Wildbad, Germany) and expressed as fold changes against sham-controls.

\section{Microinjection of test agents into RVLM}

Test agents were microinjected bilaterally and sequentially into RVLM via a glass micropipette connected to a 0.5- $\mu \mathrm{L}$ Hamilton (Reno, NV, USA) microsyringe [1519]. The coordinates used were: 4.5 to $5 \mathrm{~mm}$ posterior to the lambda, 1.8 to $2.1 \mathrm{~mm}$ lateral to the midline and 8.1 to $8.4 \mathrm{~mm}$ below the dorsal surface of the cerebellum. As a routine, a total volume of $50 \mathrm{nl}$ was delivered to each side of RVLM over 2-3 min to allow for complete diffusion of the test agents to an area approximately $800 \times 800 \mu \mathrm{m}$ within the anatomical boundaries of RVLM [18]. Test agents used included a non-selective proteasome inhibitor [20], lactacystin (Calbiochem, San Diego, CA, USA); a specific inhibitor of chymotrypsin-like proteasomal activity [21], proteasome inhibitor II (Calbiochem); a general inhibitor of ubiquitin-recycling [22], ubiquitin aldehyde (Calbiochem); and a potent, reversible, competitive and active site-directed inhibitor of UCH-L1 [23], UCH-L1 inhibitor (Calbiochem). The doses were adopted from previous reports that used those test agents for the same purpose as in this study. Lactacystin or ubiquitin aldehyde was dissolved in artificial cerebrospinal fluid, and proteasome inhibitor II or UCH-L1 inhibitor was dissolved in $10 \%$ and $40 \%$ DMSO respectively. Possible volume effect of microinjection was controlled by injecting the same amount of solvent. All test agents or their vehicles were given $30 \mathrm{~min}$ before LPS administration. To avoid the confounding effects of drug interactions, each animal received only one test agent.

\section{Statistical analysis}

All values are expressed as mean \pm SEM. Changes in protein expression, real-time PCR products or enzyme activity in RVLM during each phase of experimental brain death was used for statistical analysis. One-way ANOVA was used to assess group means. This was followed by the Scheffé multiple-range test for post hoc assessment of individual means. Mortality rate was assessed by the Fisher exact test. $P<0.05$ was considered to be statistically significant.

\section{Results}

\section{Members of the UPS are present in the proteome of} RVLM

As in our recent study [13], silver-stained 2-D electrophoresis gels reproducibly resolved $699 \pm 29 \quad(n=22)$ 
protein spots in the domain of pI: $3-10$ and Mr: $11-$ $130 \mathrm{kDa}$ from RVLM (Figure 1). Based on MALDITOF mass spectrometric analysis on protein spots in the Coomassie blue-stained 2-D electrophoresis gels from randomly selected samples $(n=8)$, in conjunction with search results using the MASCOT program (Figures 1, 2, 3 and 4) we found that members of the UPS, including proteasome subunit alpha type-1, ubiquitin and UCH-L1 are present in RVLM of rats that were subject to experimental brain death and the sham-controls.

\section{Ubiquitination in RVLM remains operational during experimental brain death}

Our first series of experiments addressed the fundamental issue of whether ubiquitination in RVLM remains operational during experimental brain death. Proteomic analysis (Figure 5A) revealed that the expression of proteasome subunit alpha type- 1 remained stable throughout the three phases of our experimental endotoxemia model, in association with intravenous administration of LPS $\left(15 \mathrm{mg} \mathrm{kg}^{-1}\right)$. These observations were confirmed by the insignificant phasic changes in psma-1 mRNA as determined by real-time PCR (Figure 5B). Western blot analysis further showed that polyubiquitination in RVLM remained prevalent (Figure 6A). Moreover, the degree of polyubiquitination was augmented by pretreatment with microinjection into the bilateral RVLM of a non-selective proteasome inhibitor [20], lactacystin (1 nmol), a conventional index for preserved proteasomal activity. Measurement of enzyme activity (Figure 6B) additionally revealed that the chemotrypsin-like proteasome activity in RVLM was enhanced during experimental brain death, to be antagonized by pretreatment with lactacystin $(1 \mathrm{nmol})$. On the other hand, both trypsin-like and caspase-like activities were essentially unaltered, and were unaffected by lactacystin pretreatment (Figure 6C,D).

\section{Ubiquitination in RVLM precipitates fatality during experimental brain death}

Our second series of experiments delineated the functional significance of the operational ubiquitination in RVLM during experimental brain death. Figure 7 illustrated that, given at the dose we used $\left(15 \mathrm{mg} \mathrm{kg}^{-1}\right)$, intravenous administration of LPS induced a progressive increase in the number of animals that succumbed to endotoxemia beginning $100 \mathrm{~min}$ after administration of LPS, reaching a mortality rate of approximately $40 \%$

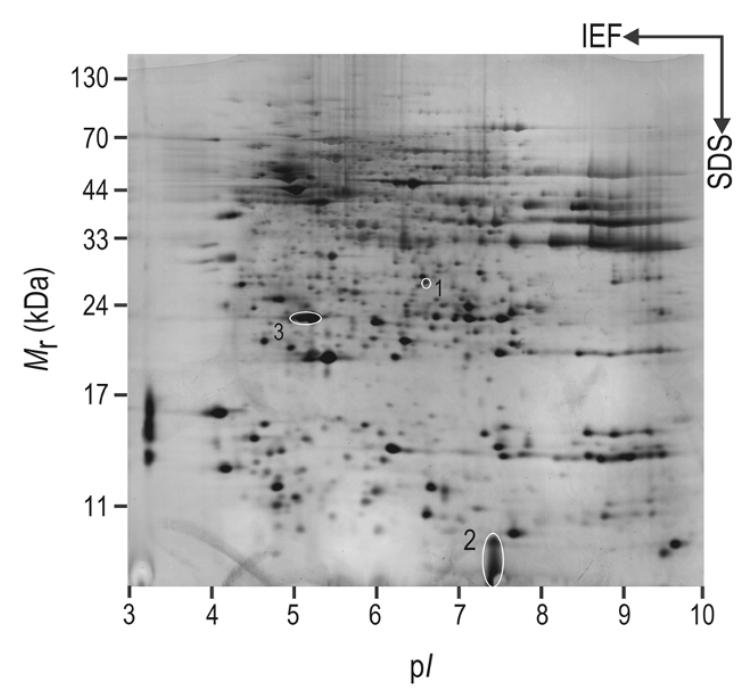

\begin{tabular}{ccccccc}
\hline \multirow{2}{*}{$\begin{array}{l}\text { Spot } \\
\text { no. }\end{array}$} & Name of protein & Accession & Sequence & MASCOT & \multicolumn{2}{c}{ Theoretical } \\
\cline { 6 - 8 } & no. & coverage $(\%)$ & score ${ }^{\text {a) }}$ & $M_{r}$ & $\mathrm{pl}$ \\
\hline 1 & Proteasome subunit alpha type-1 & $\mathrm{P} 18420$ & 30 & 72 & 29518 & 6.1 \\
2 & Ubiquitin & $\mathrm{P} 62989$ & 65 & 113 & 8565 & 6.6 \\
3 & Ubiquitin carboxyl-terminal hydrolase isozyme L1 & Q00981 & 52 & 98 & 24782 & 5.1 \\
\hline a) MASCOT MS protein score, obtained from MALDI-TOF spectra. In all cases, the probability score was $<0.05$ &
\end{tabular}

Figure 1 Members of the UPS are present in the proteomes of RVLM. Representative silver-stained 2-D electrophoresis gel of the rostral ventrolateral medulla (RVLM) showing the location of the protein spots studied. Results are representative of 22 individual samples from 22 animals. 1, proteasome subunit alpha type-1; 2, ubiquitin; 3, ubiquitin carboxyl-terminal hydrolase isozyme L1 (UCH-L1). Shown also is the identification of those proteins by MALDI-TOF analysis in association with the MASCOT search program. 


\section{A}

\section{Proteasome subunit alpha type-1}

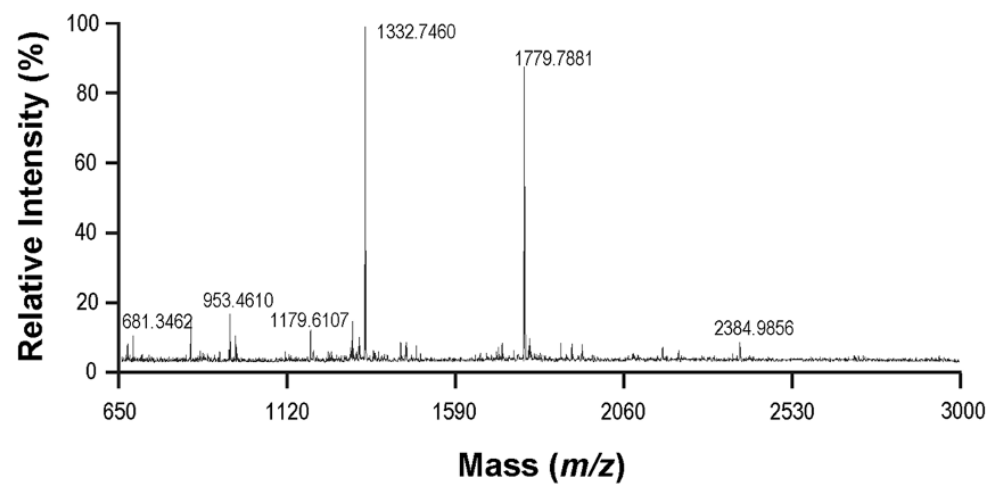

B Identification of proteasome subunit alpha type-1 based on MASCOT search program

\begin{tabular}{|c|c|c|c|c|c|c|c|}
\hline \multirow{2}{*}{ Start } & \multirow{2}{*}{ End } & \multirow{2}{*}{ Observed } & \multicolumn{2}{|c|}{$\mathrm{M}_{\mathrm{r}}$} & \multirow{2}{*}{$\Delta$} & \multirow{2}{*}{ Miss } & \multirow{2}{*}{ Sequence } \\
\hline & & & Expt & Calc & & & \\
\hline 4 & 18 & 1778.80 & 1777.79 & 1777.80 & -0.01 & 0 & NQYDNDVTVWSPQGR \\
\hline 4 & 18 & 1779.05 & 1778.05 & 1777.80 & 0.25 & 0 & NQYDNDVTVWSPQGR \\
\hline 19 & 30 & 1431.72 & 1430.72 & 1430.72 & 0.00 & 0 & IHQIEYAMEAVK \\
\hline 19 & 30 & 1447.71 & 1446.71 & 1446.72 & -0.01 & 0 & IHQIEYAMEAVK Oxidation (M) \\
\hline 97 & 107 & 1332.75 & 1331.74 & 1331.74 & 0.00 & 0 & FVFDRPLPVSR \\
\hline 116 & 122 & 843.47 & 842.46 & 842.46 & 0.00 & 0 & TQIPTQR \\
\hline 170 & 174 & 681.35 & 680.34 & 680.35 & -0.01 & 0 & TYLER \\
\hline 244 & 263 & 2166.91 & 2165.91 & 2165.92 & -0.01 & 1 & AQPSQAADEPAEKADEPMEH \\
\hline
\end{tabular}

No match to: $1296.6956,1316.4933,1475.7844,1716.8442,1791.7625,1794.7804,1881.8431,1912.8456$

C Matched peptides in proteasome subunit alpha type-1 based on MASCOT search program

\begin{tabular}{|c|c|c|c|c|c|}
\hline 1 & MFRNQYDNDV & TVWSPQGRIH & QIEYAMEAVK & QGSATVGLKS & KTHAVLVALK \\
\hline 51 & RAQSELAAHQ & KKILHVDNHI & GISIAGLTAD & ARLLCNFMRQ & ECLDSRFVFD \\
\hline 101 & RPLPVSRLVS & LIGSKTQIPT & $\underline{\mathrm{QRYGRRPYGV}}$ & GLLIAGYDDM & GPHVFQTCPS \\
\hline 151 & ANYFDCRAMS & IGARSQSART & YLERHMSEFM & QCNLDELVKH & GLRALRETLP \\
\hline 201 & AEQDLTTKNV & SIGIVGKDLE & FTIYDDDDVS & PFLDGLEERP & QRKAQPSQAA \\
\hline 251 & DEPAEKADEP & $\underline{\mathrm{MEH}}$ & & & \\
\hline
\end{tabular}

The amino acid sequences of all matched peptides are underlined.

Figure 2 Identification of proteasome subunit alpha type-1. Tryptic peptide spectrum of proteasome subunit alpha type-1 generated by MALDI-TOF mass spectrometry (A); and identification of proteasome subunit alpha type-1 based on the MASCOT search program (B,C).

within 240 min. Intriguingly, inhibiting proteasome activities by microinjection bilaterally of lactacystin $(1 \mathrm{nmol}$; Figure 7, upper diagram) or a specific inhibitor of chymotrypsin-like proteasomal activity [21], proteasome inhibitor II (1 nmol; Figure 7, lower diagram) into RVLM significantly improved the 4-h survival rate to $70-75 \%$.

\section{De-ubiquitination in RVLM also remains operational during experimental brain death}

We next investigated whether de-ubiquitination, which avails monoubiquitin (free form of ubiquitin) for optimal operation of polyubiquitination in RVLM also remains functional during experimental brain death. We found that whereas the spot volume of ubiquitin in the 2-D electrophoresis gels (Figure 8A) and monoubiquitin as determined by Western blot analysis (Figure 8B) were significantly elevated in RVLM in our experimental endotoxemia model, the mRNA level of ubiquitin remained constant (Figure $8 \mathrm{C}$ ). Likewise, superimposed on insignificantly altered protein (Figure 9A,B) and mRNA (Figure 9C) levels, UCH-L1 functionality was preserved because pretreatment with a specific UCH-L1 inhibitor (1 nmol) [23] significantly antagonized the elevated monoubiquitin level (Figure $8 \mathrm{~B}$ ).

\section{De-ubiquitination is crucially involved in maintaining survival during experimental brain death}

Our final series of experiments delineated the functional significance of de-ubiquitination in RVLM during experimental brain death. Pretreatment by microinjection 


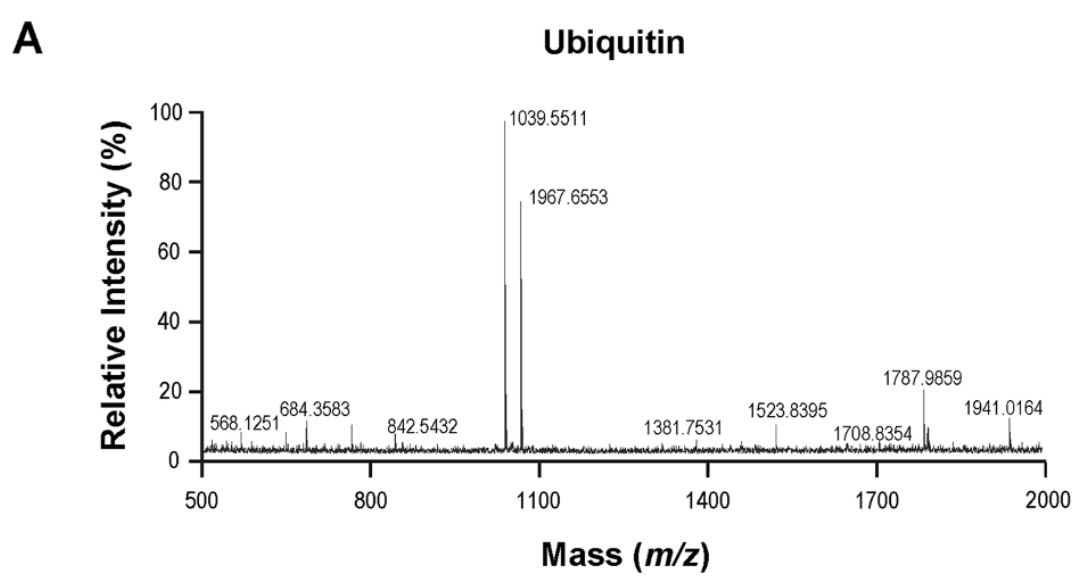

B Identification of ubiquitin based on MASCOT search program

\begin{tabular}{|c|c|c|c|c|c|c|c|}
\hline \multirow{2}{*}{ Start } & \multirow{2}{*}{ End } & \multirow{2}{*}{ Observed } & \multicolumn{2}{|c|}{$M_{r}$} & \multirow{2}{*}{$\Delta$} & \multirow{2}{*}{ Miss } & \multirow{2}{*}{ Sequence } \\
\hline & & & Expt & Calc & & & \\
\hline 1 & 6 & 765.44 & 764.43 & 764.43 & 0.00 & 0 & MQIFVK \\
\hline 12 & 27 & 1787.99 & 1786.98 & 1786.92 & 0.06 & 0 & TITLEVEPSDTIENVK \\
\hline 30 & 42 & 1523.83 & 1522.83 & 1522.77 & 0.06 & 1 & IQDKEGIPPDQQR \\
\hline 34 & 42 & 1039.55 & 1038.54 & 1038.51 & 0.03 & 0 & EGIPPDQQR \\
\hline 43 & 48 & 846.39 & 647.38 & 647.40 & -0.02 & 0 & LIFAGK \\
\hline 64 & 72 & 1067.66 & 1066.65 & 1066.61 & 0.03 & 0 & ESTLHLVLR \\
\hline
\end{tabular}

No match to: $684.3596,842.5528,1794.8937$

C Matched peptides in ubiquitin based on MASCOT search program

\begin{tabular}{cccccc}
\hline 1 & MQIFVKTLTG & KTITLEVEPS & DTIENVKAKI & QDKEGIPPDQ & QRLIFAGKQL \\
51 & EDGRTLSDYN & IQKESTLHLV & $\underline{\text { LRLRGG }}$ & & \\
\hline
\end{tabular}

The amino acid sequences of all matched peptides are underlined.

Figure 3 Identification of ubiquitin. Tryptic peptide spectrum of ubiquitin generated by MALDI-TOF mass spectrometry (A); and identification of ubiquitin based on the MASCOT search program $(\mathbf{B}, \mathbf{C})$.

bilaterally into RVLM of a general inhibitor of ubiquitinrecycling [22], ubiquitin aldehyde, at a very low dose of 5 fmol, was effective in reducing the survival rate by $40 \%$ within 10 min after the initiation of experimental endotoxemia, reaching $60 \%$ mortality by $80 \mathrm{~min}$ (Figure 10, upper diagram). Increasing the dose to $50 \mathrm{fmol}$ exacerbated the mortality rate to $80 \%$ by $20 \mathrm{~min}$, with all animals succumbed to endotoxemia by $110 \mathrm{~min}$. Pretreatment with ubiquitin aldehyde at 5 pmol resulted in $100 \%$ mortality within 5-10 min after the administration of LPS. Specific inhibition of UCH-LI (1 nmole) in RVLM also significantly reduced survival rate that began within the first $20 \mathrm{~min}$ in animals subject to experimental endotoxemia, leading to a survival rate of $10 \%$ by the end of $240 \mathrm{~min}$ (Figure 10, lower diagram).

\section{Discussion}

The UPS has emerged in recent years as a central player under physiological and pathological conditions in the regulation of diverse cellular processes. In addition to degradation of abnormal proteins, the UPS is responsible for the recognition and degradation of ubiquitinated substrate such as proteins involved in cell cycle regulation, transcriptional regulation, receptor function, signal transduction, endocytosis, antigen presentation, aging, stress responses or apoptosis $[8,9,24,25]$. Aberrations in either the process of ubiquitination or de-ubiquitination have also been directly implicated in the etiology of many diseases $[8,9]$, including cardiomyopathy [26]. Based on an endotoxemia model and in conjunction with proteomics, Western blot, real-time PCR, enzyme activity and survival evaluations, the present study revealed that augmented polyubiquitination, enhanced proteasomal activities and recycling of ubiquitin through sustained de-ubiquitination in RVLM play a vital role during brain death.

As reflected by Hershko [27], the discovery of the UPS was originally driven by the notion that intracellular protein degradation is energy-dependent. It is since known that two ATP-dependent steps are present during 


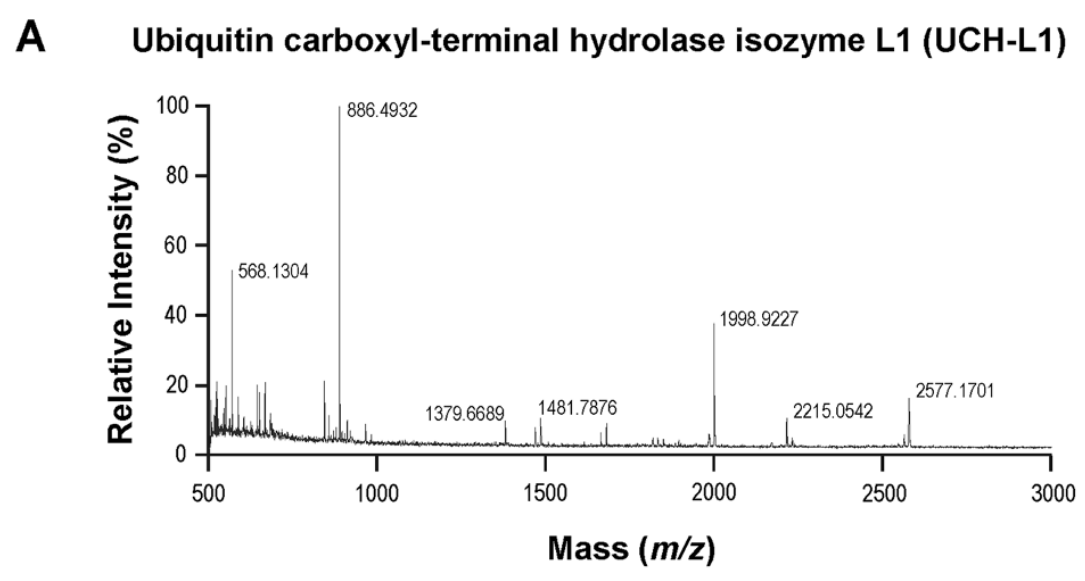

B Identification of UCH-L1 based on MASCOT search program

\begin{tabular}{|c|c|c|c|c|c|c|c|}
\hline \multirow{2}{*}{ Start } & \multirow{2}{*}{ End } & \multirow{2}{*}{ Observed } & \multicolumn{2}{|c|}{$\mathrm{M}_{\mathrm{r}}$} & \multirow{2}{*}{$\Delta$} & \multirow{2}{*}{ Miss } & \multirow{2}{*}{ Sequence } \\
\hline & & & Expt & Calc & & & \\
\hline 1 & 15 & 1831.86 & 1830.85 & 1830.90 & -0.05 & 0 & MQLKPMEINPEMLNK Oxidation (M) \\
\hline 20 & 27 & 886.49 & 885.49 & 885.48 & 0.00 & 0 & LGVAGQWR \\
\hline 66 & 78 & 1484.79 & 1483.78 & 1483.79 & -0.01 & 1 & QIEELKGQEVSPK \\
\hline 79 & 83 & 687.31 & 686.30 & 686.35 & -0.05 & 0 & VYFMK \\
\hline 79 & 83 & 703.29 & 702.29 & 702.34 & -0.05 & 0 & VYFMK Oxidation (M) \\
\hline 116 & 129 & 1678.84 & 1677.83 & 1677.82 & 0.01 & 1 & QFLSETEKLSPEDR \\
\hline 179 & 199 & 2214.05 & 2213.04 & 2213.04 & 0.00 & 0 & MPFPVNHGASSEDSLLQDAAK \\
\hline 179 & 199 & 2230.04 & 2229.03 & 2229.04 & 0.00 & 0 & MPFPVNHGASSEDSLLQDAAK \\
\hline 203 & 213 & 1379.67 & 1378.66 & 1378.65 & 0.01 & 1 & EFTEREQGEVR \\
\hline
\end{tabular}

No match to: $893.01,902.47,908.46,909.46,916.32,918.45,964.46,1467.78,1661.82,1983.87,1997.92,2562.14,2576.17$

C Matched peptides in UCH-L1 based on MASCOT search program

\begin{tabular}{clllll}
\hline 1 & MQLKPMEINP & EMLNKVLAKL & GVAGQWRFAD & VLGLEEEILG & SVPSPACALL \\
\cline { 5 - 6 } & LLFPLTAQHE & NFRKKQIEEL & KGQEVSPKVY & FMKQTIGNSC & GTIGLMHAVA \\
101 & NNQDNLGFED & GSVLKQFLSE & TEKLSPEDRA & KCFEKNEAIQ & AAHDSVAQEG \\
151 & QCRVDDKVNF & HFILFNNVDG & HLYELDGRMP & FPVNHGASSE & DSLLQDAAKV \\
201 & CREFTEREQG & EVRFSAVALC & KAA & & \\
\hline
\end{tabular}

The amino acid sequences of all matched peptides are underlined.

Figure 4 Identification of UCH-L1. Tryptic peptide spectrum of UCH-L1 generated by MALDI-TOF mass spectrometry (A); and identification of UCH-L1 based on the MASCOT search program $(\mathbf{B}, \mathbf{C})$.

ubiquitination; formation of a high-energy thiolester bond between ubiquitin and the ubiquitin-activating enzyme and degradation of ubiquitinylated proteins by the $26 \mathrm{~S}$ proteasome complex $[8,9]$. In this context, it is intriguing to note that enzyme assay for activity in or electron transport capacity between respiratory chain complexes in our previously study [28] revealed that the progressive reduction in neuronal activity at RVLM in our experimental endotoxemia model of brain death is associated with bioenergetic failure because of mitochondrial dysfunction. An immediate corollary to those observations is that the process of polyubiquitination and proteasomal degradation in RVLM should be progressively compromised during brain death. On the contrary, we observed in the present study that despite minimal alterations in proteasome subunit alpha type 1 mRNA and protein, there was sustained polyubiquitination and enhanced proteasomal activity in RVLM during experimental brain death. By demonstrating that RVLM is a high metabolic energy-required region in brain, we speculated in a recent study [13] that "the presence of higher levels of tissue oxygen and ATP synthase subunits in RVLM, leading to augmented ATP production, provides a cellular safeguard mechanism to reduce the possibility of irreversible reduction in intracellular ATP contents that precipitate brain death". Results from pretreatments with lactacystin or proteasome inhibitor II on survival in the present study, however, suggest that one of the targets of this cellular safeguard mechanism is polyubiquitination and proteasomal degradation of the 

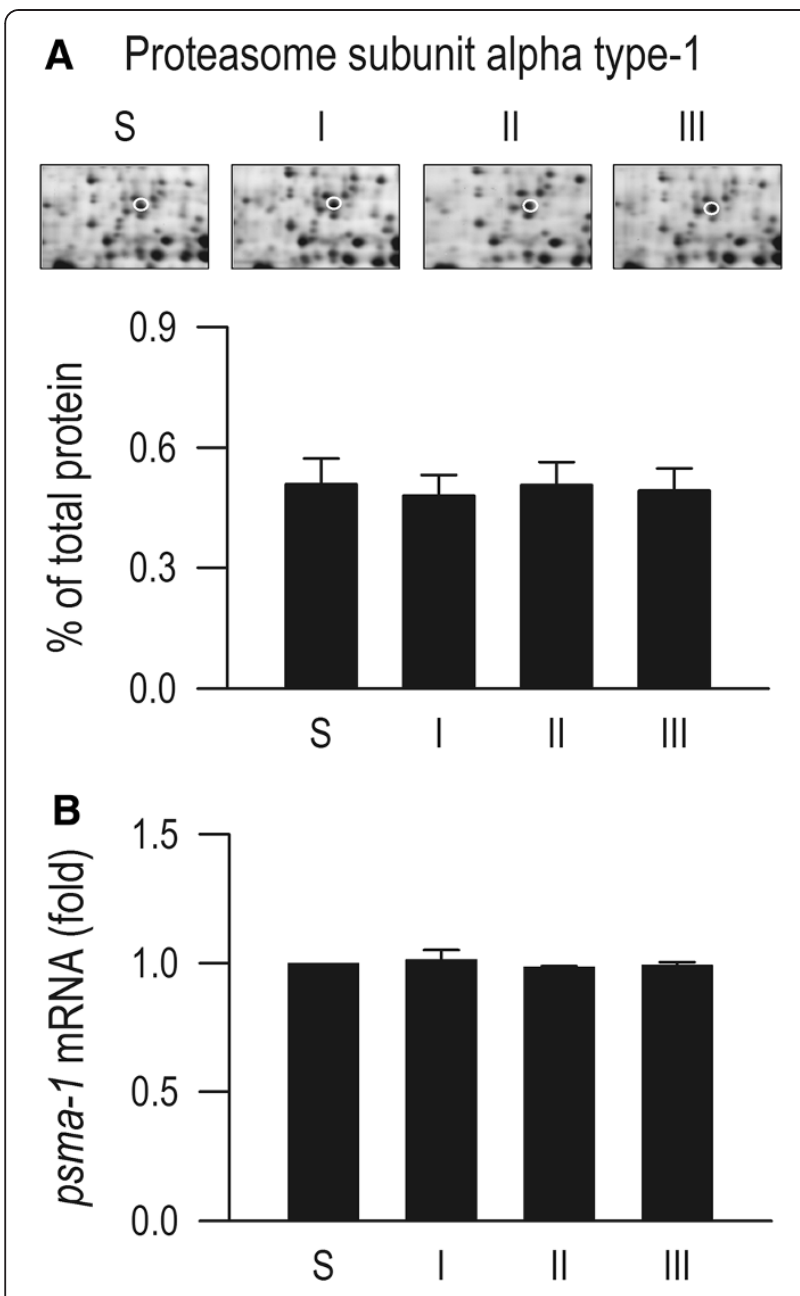

Figure 5 Ubiquitination in RVLM remains operational during experimental brain death. Phasic changes in spot volume of proteasome subunit alpha type-1 in the proteomic map of RVLM (A) or fold changes against sham-controls of psma-1 mRNA determined by real-time PCR (B) in RVLM of rats that received intravenous administration of LPS $\left(15 \mathrm{mg} \mathrm{kg}^{-1}\right)$. In this and Figures 6,8 and 9, S denotes samples obtained from sham-controls, and I, II or III denotes samples obtained during the peak of Phases I, II or III in our experimental endotoxemia model of brain death. Values are mean \pm SEM, $n=5-6$ animals per experimental group. No statistical significance $(P>0.05)$ found among all groups in one-way ANOVA.

pro-life proteins in RVLM during experimental brain death.

Optimal operation of polyubiquitination (conjugation of protein substrates by ubiquitin) also depends on the availability of monoubiquitin (free form of ubiquitin), which is regulated by the de-ubiquitinating enzymes [10]. By showing the effectiveness of ubiquitin aldehyde at fmol concentration to exacerbate mortality rate, the present study revealed that recycling of ubiquitin in RVLM is actively executed and is vitally involved in the maintenance of survival in our experimental endotoxemia model of brain death. Of the known de-ubiquitination enzymes, $\mathrm{UCH}-\mathrm{L} 1$ is among the most abundantly present proteins in brain [12]. Our laboratory reported previously that UCH-L1 in RVLM is crucial to survival during intoxication induced by the organophosphate poison mevinphos [29]. The present study further showed that superimposed on minimal alterations in UCH-LI mRNA and protein, there is an enhanced availability in free ubiquitin that was suppressed by UCH-L1 inhibitor. Furthermore, on an equimolar basis $(1 \mathrm{nmol})$, the degree of improvement of survival rate by lactacystin or proteasome inhibitor II was significantly less than the detrimental effects of UCH-L1 inhibitor. There are two potential interpretations on those results. First, despite the lack of de novo synthesis, the abundantly present UCH-L1 in RVLM may be sufficient to avail additional recycled monoubiquitin through active de-ubiquitination to sustain the elevated polyubiquitination. Second, the augmented polyubiquitination favors maintenance of survival by promoting the degradation of pro-death proteins in RVLM during experimental brain death. Further studies are required to delineate the mechanisms via which the de-ubiquitination processes and subsequent polyubiquitination may target preferentially the pro-death proteins.

Our laboratory proposed previously [7] that the fundamental conceptual backbone in the pursuit of the cellular and molecular mechanisms that underlie brain death is that the progression towards death entails multiple tugof-wars between pro-death and pro-life programs in RVLM [7]. It is therefore conceivable that ubiquitination or de-ubiquitination in RVLM participate in brain death by regulating the degradation of the proteins involved in those programs. One of the best-known targets of the UPS is activation of the inducible transcription factor nuclear factor- $\kappa \mathrm{B}(\mathrm{NF}-\kappa \mathrm{B})[30,31]$. NF- $-\mathrm{kB}$ is retained in a latent form in the cytoplasm of non-stimulated cells by inhibitory molecules collectively termed inhibitory- $\mathrm{KB}$ (ІкB). Stimuli that induce NF-кB activation target IкB to site-specific phosphorylation, leading to its degradation by the UPS. Following IкB degradation, NF- $\kappa B$ is translocated to the nucleus as an active transcription factor that is able to induce its target genes. It is thus of interest that, based on an experimental endotoxemia model, our laboratory found previously $[15,17,32]$ that the advancement towards brain death is associated with the progressive augmentation in both molecular synthesis and functional expression of nitric oxide synthase II (NOS II) in RVLM. We further showed that transcriptional regulation by NF- $\mathrm{KB}$ is crucial to the expression of NOS II gene [15]. At the same time, a number of reports suggest that the UPS may also be involved in the degradation of NOS II [33,34]. It follows that the UPS may participate actively in brain death by regulating both the synthesis 
A
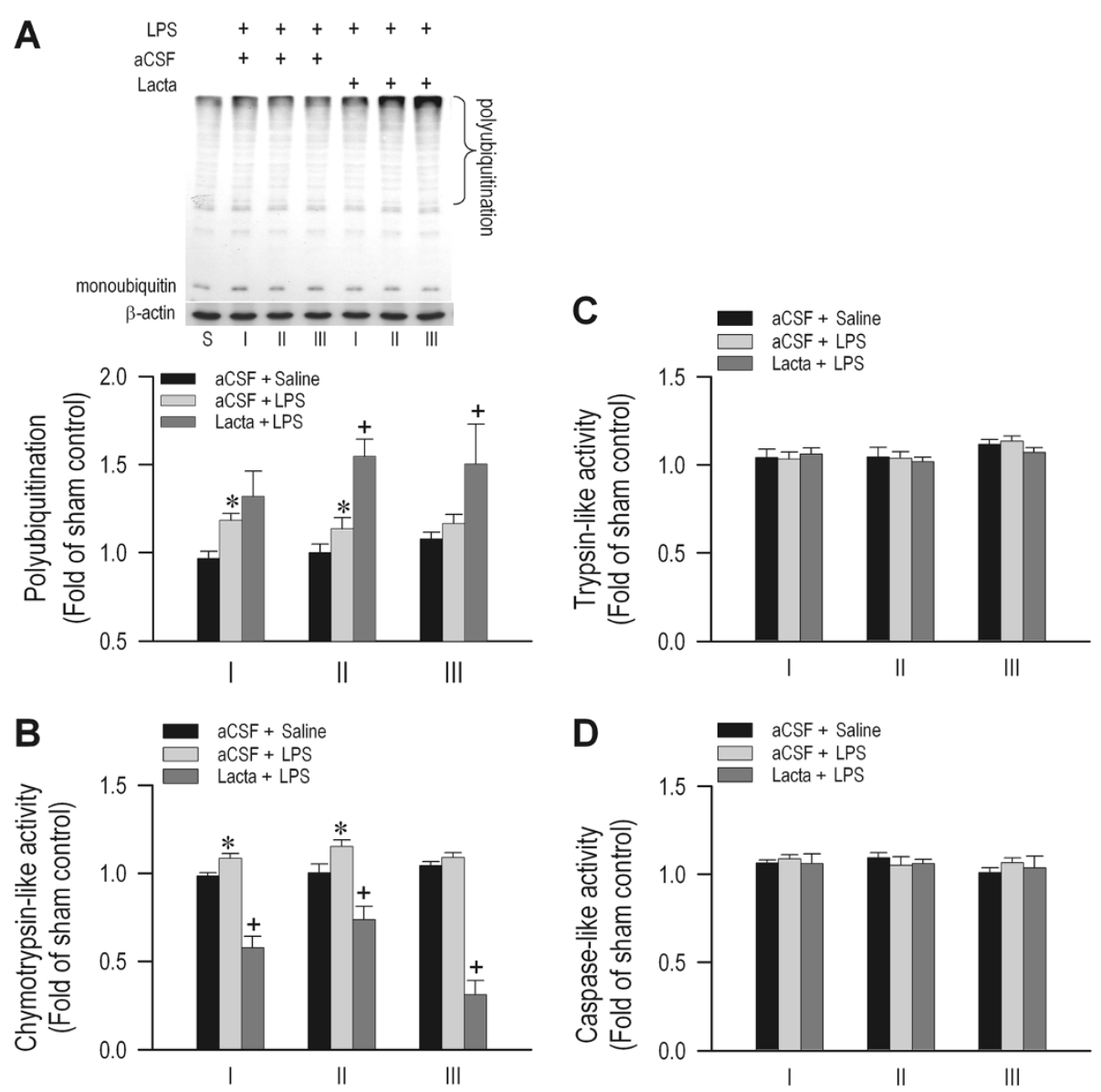

Figure 6 Maintained polyubiquitination and preserved proteasomal activity in RVLM during experimental brain death. Illustrative gels or summary of phasic fold changes against sham-controls in polyubiquitinated proteins detected by Western blot analysis (A) or chemotrypsin-like (B), trypsin-like (C) and caspase-like (D) proteasome activity in RVLM of rats that received pretreatment by microinjection bilaterally into RVLM of lactacystin (Lacta; $1 \mathrm{nmol}$ ) or artificial cerebrospinal fluid (aCSF), followed by intravenous administration of LPS (15 $\mathrm{mg} \mathrm{kg}^{-1}$ ) or saline. Values are mean \pm SEM, $n=5-6$ animals per experimental group. ${ }^{*} \mathrm{P}<0.05$ versus aCSF + Saline group, and ${ }^{+} \mathrm{P}<0.05$ versus aCSF + LPS group at corresponding phases in the Scheffé multiple-range test.

(via activation of NF-kB through IкB degradation) and degradation of NOS II in RVLM. Our laboratory demonstrated recently [35] that the UPS at RVLM indeed plays such a double-edged sword role in brain death. Specifically, we showed that a crucial determinant for the prevalence of NOS II in RVLM during brain death resides in the temporal balance between its continuous degradation and the progressively augmented synthesis. In concordance with findings in the present study, we further found that recycling of ubiquitin in RVLM through sustained de-ubiquitination is crucial to uninterrupted degradation of NOS II, which is essential for the maintenance of survival. It should be mentioned that in addition to the UPS, other signaling systems in RVLM are also engaged in experimental brain death. For example, the molecular synthesis of NOS I in RVLM, which is crucial to the prolife process $[15,18,32]$, is downstream to the hypoxia-inducible factor-1/heme oxygenase-1/heat shock protein
70 cascade $[18,36]$; and hypoxia-inducible factor- 1 is stabilized by sumoylation [37].

\section{Conclusion}

In conclusion, based on an experimental endotoxemia model, the present study provided novel findings to support the notion that both ubiquitination and de-ubiquitination in RVLM participate in brain death. We found that polyubiquitination was augmented, proteasomal activities were enhanced and recycling of ubiquitin was sustained through de-ubiquitination in RVLM during experimental brain death. We stipulate that the UPS is engaged in the multiple tug-of-wars between pro-death and pro-life programs in RVLM during the progression towards brain death by regulating the degradation of the proteins involved. This information will offer important insights into the etiology of brain death and shall be invaluable to future development of management strategies against this fatal eventuality. 


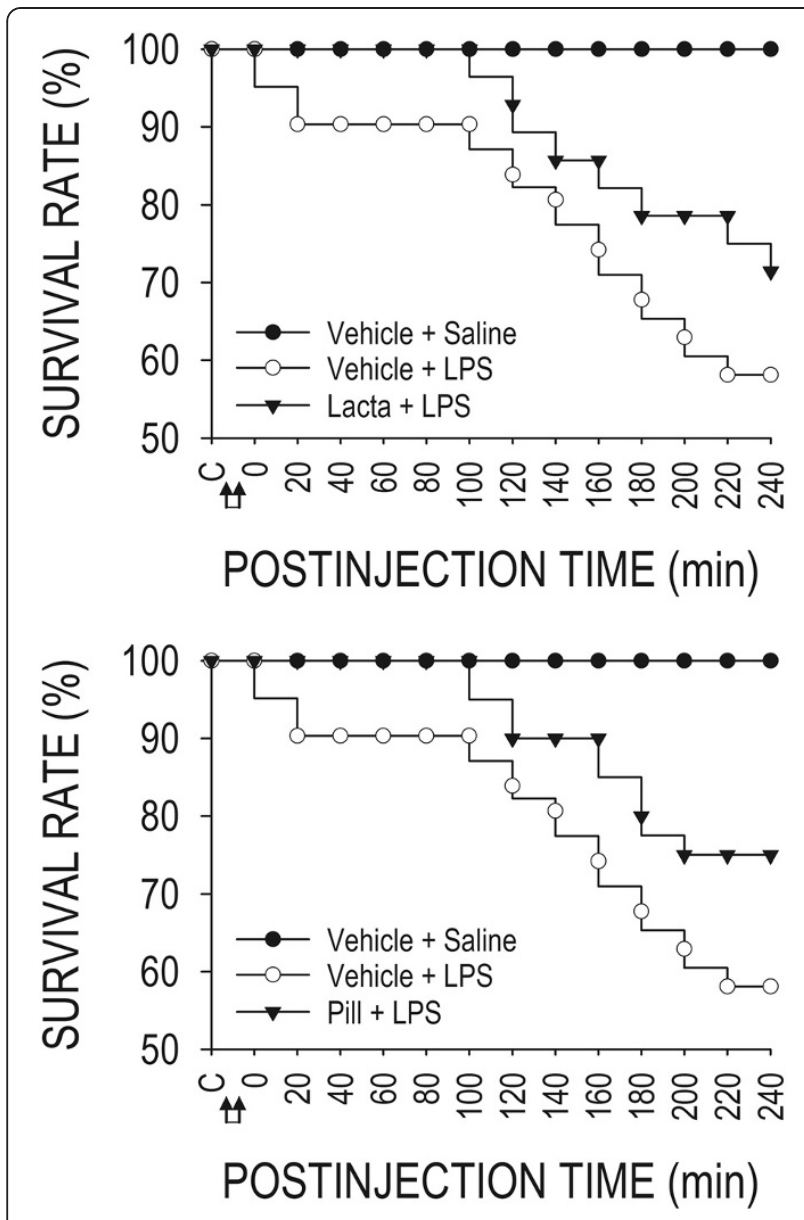

Figure 7 Ubiquitination in RVLM precipitates fatality during experimental brain death. Survival rate of rats that received pretreatment by microinjection bilaterally into RVLM of lactacystin (Lacta; $1 \mathrm{nmol}$ ) (upper diagram), proteasome inhibitor II (Pill; $1 \mathrm{nmol}$ ) (lower diagram) or their solvents (Vehicle), followed by intravenous administration (at arrows) of LPS $\left(15 \mathrm{mg} \mathrm{kg}^{-1}\right)$ or saline. Values are mean $\pm \mathrm{SEM}, \mathrm{n}=7-8$ animals at the beginning of the experiment. Significant difference versus Vehicle + LPS group in the Fisher exact test.

\section{Abbreviation}

DTT: Dithiothreitol; IEF: Isoelectric focusing; IKB: Inhibitory-KB;

IPG: Immobilized pH gradient; LF component: Low-frequency component; LPS: Lipopolysaccharide; NF-KB: Nuclear factor-KB; NOS I: Nitric oxide synthase I; NOS II: Nitric oxide synthase II; RVLM: Rostral ventrolateral medulla; SAP: Systemic arterial blood pressure; SDS: Sodium dodecyl sulfate; TCA: Trichloroacetic acid; TFA: Trifluoroacetic acid; UCHs: Ubiquitin C-terminal hydrolases; UCH-L1: Ubiquitin C-terminal hydrolase isozyme-L1; UPS: Ubiquitin-proteasome system.

\section{Competing interests}

The authors declare that they have no competing financial interests.

\section{Acknowledgements}

This work was supported by the National Science Council (NSC-96-2320-B110-002 and NSC-97-2320-B-182A-007-MY3 to SHHC; NSC-97-2752-B-110-002PAE, NSC-96-2752-B-110-002-PAE, and NSC-100-2321-B-182A-006 to AYWC), and Chang Gung Memorial Hospital (CMRPG871341 and CLRPG871342 to SHHC), Taiwan, Republic of China.
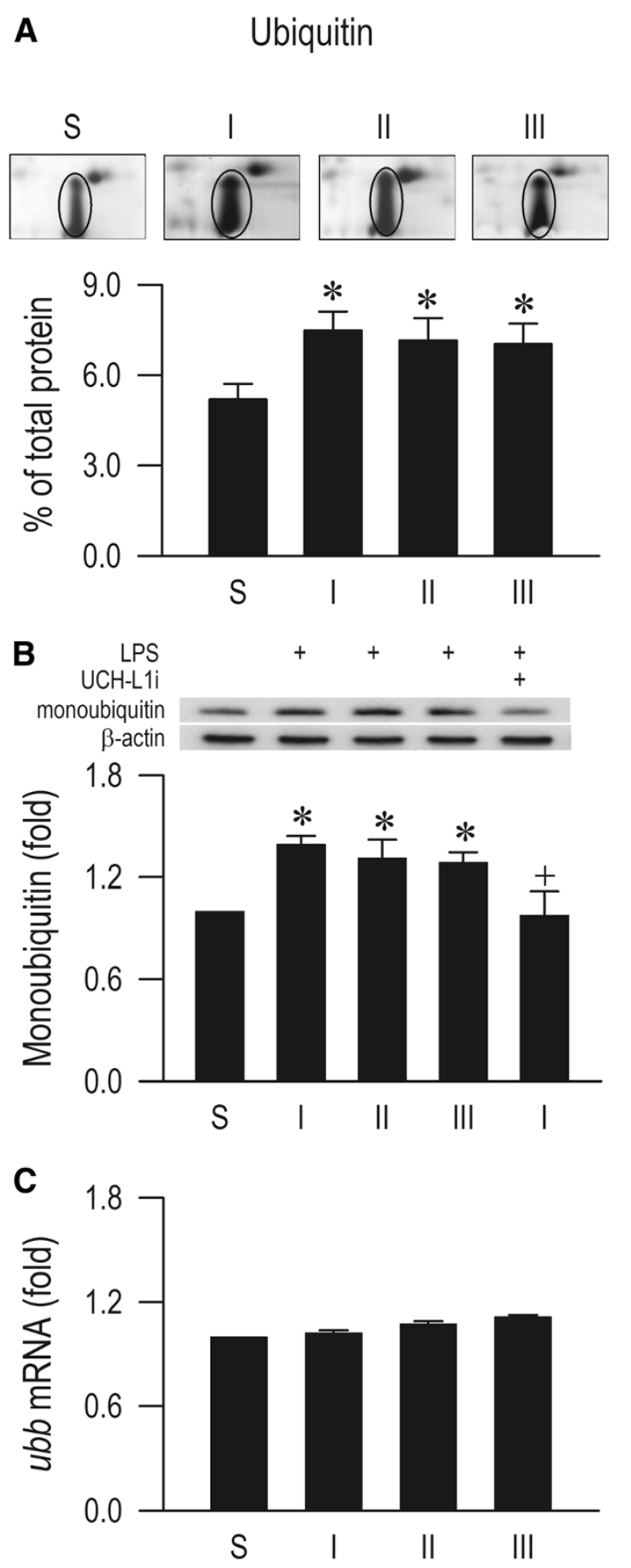

Figure 8 De-ubiquitination in RVLM also remains operational during experimental brain death. Phasic changes in spot volume of ubiquitin in the proteomic map of RVLM $(\mathbf{A})$; fold changes against sham-controls of monoubiquitin detected by Western blot analysis (B) or ubb mRNA determined by real-time PCR (C) in RVLM of rats that received intravenous administration of LPS (15 mg kg-1), alone or with additional pretreatment by microinjection into bilateral RVLM of UCH-L1 inhibitor (UCH-L1i; 1 nmol). Values are mean \pm SEM, $n=5-$ 6 animals per experimental group. ${ }^{*} \mathrm{P}<0.05$ versus sham-control group, and ${ }^{+} \mathrm{P}<0.05$ versus LPS group at corresponding phase in the Scheffé multiple-range test. 


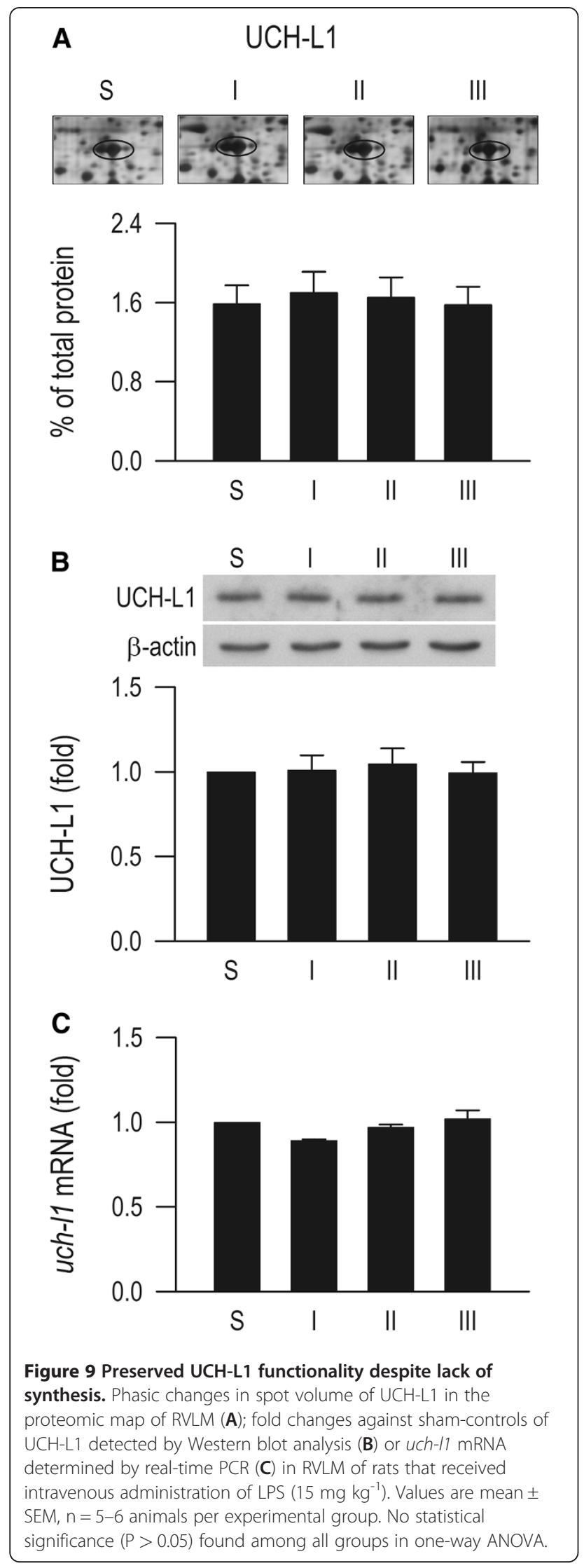

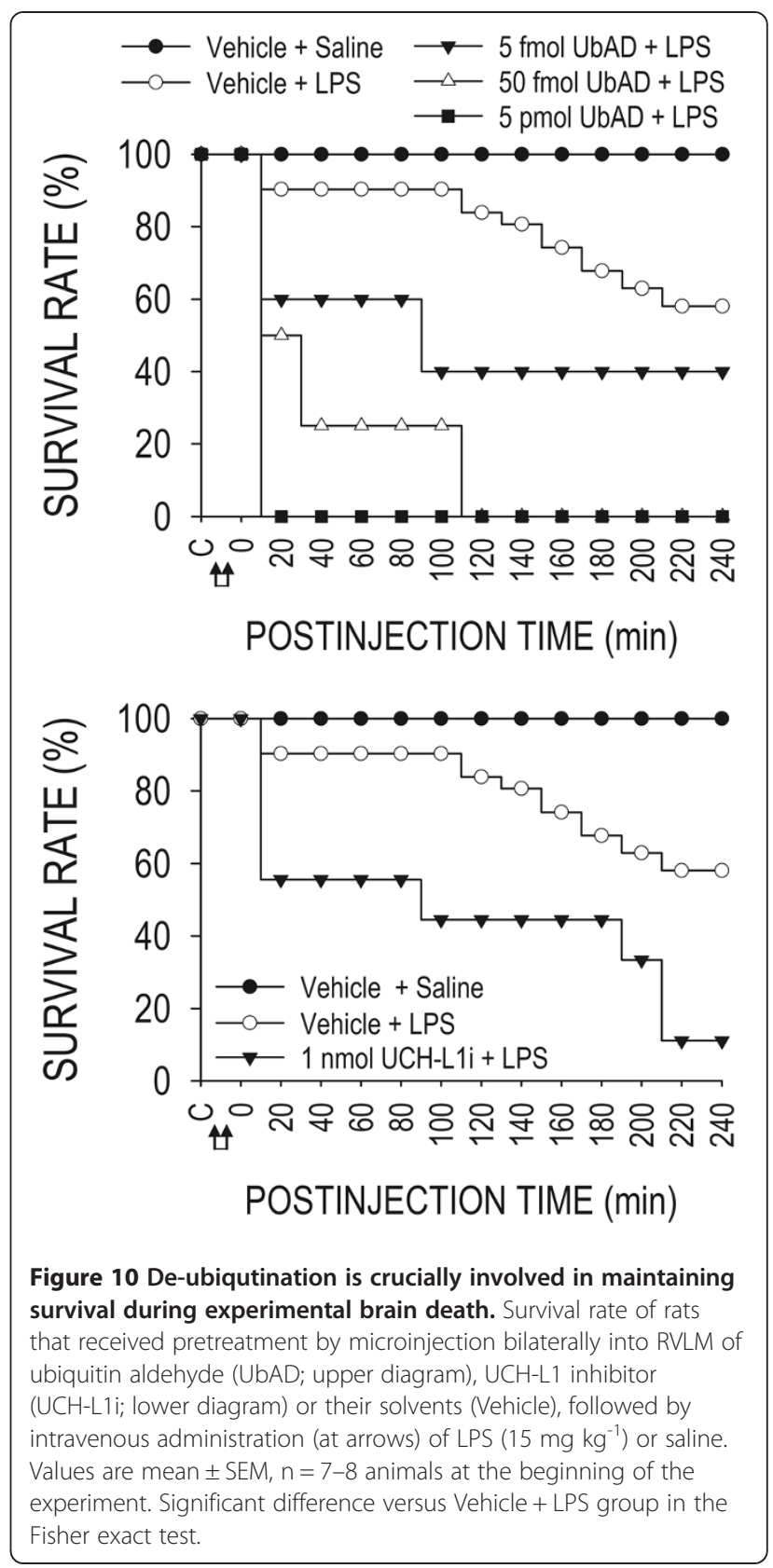

Author details

${ }^{1}$ Center for Translational Research in Biomedical Sciences, Kaohsiung Chang Gung Memorial Hospital, Kaohsiung 83301, Taiwan, Republic of China. ${ }^{2}$ Institute of Biomedical Science, National Sun Yat-sen University, Kaohsiung 80424, Taiwan, Republic of China.

\section{Authors' contributions}

CHYW performed the experiments. JLJC performed the proteomic experiments. JYHC participated in experimental design. SHHC and AYWC conceived the study, participated in experimental design, and drafted and revised the manuscript. All authors have read and approved the final manuscript.

Received: 6 February 2012 Accepted: 30 April 2012 Published: 30 April 2012 


\section{References}

1. Wijdicks EFM, Varelas PN, Gronseth GS, Greer DM: Evidence-based guide update: determining brain death in adults. Neurology 2010, 74:1911-1918

2. Kuo TBJ, Chan SHH: Continuous, on-line, real-time spectral analysis of systemic arterial pressure signals. Am J Physiol 1993, 264:H2208-H2213.

3. Yien HW, Hseu SS, Lee LC, Kuo TBJ, Lee TY, Chan SHH: Spectral analysis of systemic arterial pressure and heart rate signals as a prognostic tool for the prediction of patient outcome in intensive care unit. Crit Care Med 1997, 25:258-266.

4. Yen DHT, Yien HW, Wang LM, Lee $\mathrm{CH}$, Chan SHH: Spectral analysis of systemic arterial pressure and heart rate signals of patients with acute respiratory failure induced by severe organophosphate poisoning. Crit Care Med 2000, 28:2805-2811.

5. Kuo TBJ, Yien HW, Hseu SS, Yang CCH, Lin YY, Lee LC, Chan SHH: Diminished vasomotor component of systemic arterial pressure signals and baroreflex in brain death. Am J Physiol 1997, 273:H1291-H1298.

6. Kuo TBJ, Yang $\mathrm{CCH}$, Chan $\mathrm{SHH}$ : Selective activation of vasomotor components of SAP spectrum by nucleus reticularis ventrolateralis in the rat. Am J Physiol 1997, 272:H485-H492.

7. Chan JYH, Chang AYW, Chan SHH: New insights on brain stem death: from bedside to bench. Prog Neurobiol 2005, 77:396-425

8. Ciechanover A, Schwartz AL: The ubiquitin-proteasome pathway: the complexity and myriad functions of proteins death. Proc Natl Acad Sci USA 1998, 95:2727-2730

9. Glickman MH, Ciechanover A: The ubiquitin-proteasome proteolytic pathway: destruction for the sake of construction. Physiol Rev 2002, 82:373-428.

10. Wilkinson KD: Regulation of ubiquitin-dependent processes by deubiquitinating enzymes. FASEB J 1997, 11:1245-1256.

11. Larsen CN, Krantz BA, Wilkinson KD: Substrate specificity of deubiquitinating enzymes: ubiquitin C-terminal hydrolases. Biochemistry 1998, 37:3358-3368.

12. Doran JF, Jackson P, Kynoch PAM, Thompson RJ: Isolation of PGP 9.5, a new human neurone-specific protein detected by high-resolution two-dimensional electrophoresis. J Neurochem 1983, 40:1542-1547.

13. Chou JL, Wu CHY, Tsai CY, Chang AYW, Chan SHH: Proteomic investigation of a neural substrate intimately related to brain death. Proteomics 2011, 11:239-248.

14. Yang CH, Shyr MH, Kuo TBJ, Tan PPC, Chan SHH: Effects of propofol on nociceptive response and power spectra of electroencephalographic and systemic arterial pressure signals in the rat: correlation with plasma concentration. J Pharmacol Exp Ther 1995, 275:1568-1574.

15. Chan JYH, Ou CC, Wang LL, Chan SHH: Heat shock protein 70 confers cardiovascular protection during endotoxemia via inhibition of nuclear factor- $\nabla \mathrm{B}$ activation and inducible nitric oxide synthase expression in rostral ventrolateral medulla. Circulation 2004, 110:3560-3566.

16. Chang AYW, Chan JYH, Chou JL, Li FCH, Dai KY, Chan SHH: Heat shock protein 60 in rostral ventrolateral medulla reduces cardiovascular fatality during endotoxemia in the rat. J Physiol 2006, 574:547-564.

17. Chan JYH, Chang AYW, Wang LL, Ou CC, Chan SHH: Protein kinase C-dependent mitochondrial translocation of proapoptotic protein Bax on activation of inducible nitric-oxide synthase in rostral ventrolateral medulla mediates cardiovascular depression during experimental endotoxemia. Mol Pharmacol 2007, 71:1129-1139.

18. Chan JYH, Cheng HL, Chou JU, Li FCH, Dai KY, Chan SHH, Chang AYW: Heat shock protein 60 or 70 activates NOS I- and inhibits NOS II-associated signaling, and depresses mitochondrial apoptotic cascade during brain stem death. J Biol Chem 2007, 282:4585-4600

19. Chan JYH, Wu CHY, Tsai CY, Cheng HL, Dai KY, Chan SHH, Chang AYW: Transcriptional upregulation of nitric oxide synthase II by nuclear factor-KB at rostral ventrolateral medulla in mevinphos intoxication model of brain stem death. J Physiol 2007, 581:12931307.

20. Fenteany G, Standaert RF, Lane WS, Choi S, Corey EJ, Schreiber SL: Inhibition of proteasome activities and subunit-specific amino-terminal threonine modification by lactacystin. Science 1996, 268:725-731.

21. Vinitsky A, Michaud C, Powers JC, Orlowski M: Inhibition of the chymotrypsin-like activity of the pituitary multicatalytic proteinase complex. Biochemistry 1992, 31:9421-9428.

22. Hershko A, Rose IA: Ubiquitin-aldehyde: a general inhibitor of ubiquitinrecyling processes. Proc Natl Acad Sci USA 1987, 84:1829-1833.
23. Liu Y, Lashuel HA, Choi S, Xing X, Case A, Ni J, Yeh LA, Cuny GD, Stein RL, Lansbury PT Jr: Discovery of inhibitors that elucidate the role of UCH-L1 activity in the H1299 lung cancer cell line. Chem Biol 2003, 10:837-846.

24. Thompson SJ, Loftus LT, Ashley MD, Meller R: Ubiquitin-proteasome system as a modulator of cell fate. Curr Opin Pharmacol 2008, 8:90-95.

25. Bernassola F, Ciechanover A, Melino G: The ubiquitin proteasome system and its involvement in cell death pathways. Cell Death Differ 2010, 17:1-3.

26. Weekes J, Morrison K, Mullen A, Wait R, Barton P, Dunn MJ: Hyperubiquitination of proteins in dilated cardiomyopathy. Proteomics 2003, 3:208-216.

27. Hershko A: Lessons from the discovery of the ubiquitin system. Trends Biochem Sci 1996, 21:445-449.

28. Chuang YC, Chan JYH, Chang AYW, Sikorska M, Borowy-Borowski H, Liou CW, Chan SHH: Neuroprotective effects of coenzyme $Q_{10}$ at rostral ventrolateral medulla against fatality during experimental endotoxemia in the rat. Shock 2003, 19:427-432.

29. Chang C, Chang AYW, Chan SHH: De novo synthesis of ubiquitin carboxyl-terminal hydrolase isozyme-L1 in rostral ventrolateral medulla is crucial to survival during mevinphos intoxication. Shock 2004, 11:748-755.

30. Yaron A, Gonen H, Alkalay I, Hatzubai A, Jung S, Beyth S, Mercurio F, Manning AM, Ciechanover A, Ben-Neriah Y: Inhibition of NF-KB cellular function via specific targeting of the IKB-ubiquitin ligase. EMBO J 1997 16:6486-6494

31. Karin $\mathrm{M}$, Ben-Neriah Y: Phosphorylation meets ubiquitination: the control of NF-KB activity. Annu Rev Immunol 2000, 18:621-663.

32. Chan JYH, Wang SH, Chan SHH: Differential roles of iNOS and nNOS at rostral ventrolateral medulla during experimental endotoxemia in the rat. Shock 2001, 15:65-72.

33. Kolodziejski PJ, Musial A, Koo JS, Eissa NT: Ubiquitination of inducible nitric oxide synthase is required for its degradation. Proc Natl Acad Sci USA 2002, 99:12315-12320.

34. Ying WZ, Sanders PW: Accelerated ubiquitination and proteasome degradation of a genetic variant of inducible nitric oxide synthase. Biochem J 2003, 376:789-794.

35. Wu CHY, Chan JYH, Chan SHH, Chang AYW: A double-edged sword role for ubiquitin-proteasome system in brain stem cardiovascular regulation during experimental brain death. PLoS One 2011, 6:e27404.

36. Chang AYW, Chan JYH, Cheng HL, Tsai CY, Chan SHH: Hypoxia-inducible factor-1/heme oxygenase-1 cascade as upstream signals in the pro-life role of heat shock protein 70 at rostral ventrolateral medulla during experimental brain stem death. Shock 2009, 32:651-658.

37. Chan JYH, Tsai CY, Wu CHY, Li FCH, Dai KY, Sun EYH, Chan SHH, Chang AYW: Sumoylation of hypoxia-inducible factor-1 ameliorates failure of brain stem cardiovascular regulation in experimental brain death. PLOS One 2011, 6:e17375.

doi:10.1186/1423-0127-19-48

Cite this article as: Wu et al:: Engagement of ubiquitination and de-ubiquitination at rostral ventrolateral medulla in experimental brain death. Journal of Biomedical Science 2012 19:48.

\section{Submit your next manuscript to BioMed Central and take full advantage of:}

- Convenient online submission

- Thorough peer review

- No space constraints or color figure charges

- Immediate publication on acceptance

- Inclusion in PubMed, CAS, Scopus and Google Scholar

- Research which is freely available for redistribution 